\title{
A PESQUISA EM EDUCAÇÃO: APORTES PSICANALÍTICOS
}

\author{
RESEARCH IN EDUCATION: CONTRIBUTIONS FROM PSYCHOANALYSIS
}

LA INVESTIGACIÓN EN EDUCACIÓN: APORTES PSICOANALÍTICOS

\section{Maria Angélica Augusto de Mello Pisetta ${ }^{1}$}

\section{Simone Bicca Charczuk ${ }^{2}$}

${ }^{1}$ Doutora em Psicologia pela UFRJ. Docente do Programa de Pós-Graduação em Educação da Universidade Federal Fluminense (UFF), Niterói, RJ, Brasil.

2Doutora em Educação pela UFRGS. Docente do Departamento de Estudos Básicos da Faculdade de Educação da Universidade Federal do Rio Grande do Sul (UFRGS), Porto Alegre, RS, Brasil.

Resumo: No que se apresenta, propomo-nos a discutir a relação entre psicanálise e educação, analisando conceitos psicanalíticos fundamentais como operadores de leitura na realização de pesquisas. Problematizamos os conceitos de inconsciente e Outro, acentuando sua dimensão política. Encontros possíveis entre as duas áreas são pontuados, sublinhando a articulação entre psicanálise, educação e pesquisa. Especificidades da pesquisa são referenciadas e analisamos os conceitos de transferência, associação livre, discurso e escuta como ferramentas metodológicas na abordagem da pesquisa. Por fim, compartilhamos propostas de estudos realizadas atualmente nas quais se aplicam recursos metodológicos construídos pelo aporte psicanalítico.

Palavras-chave: Psicanálise; Educação; Pesquisa.

Abstract: In this work we discuss the relationship between psychoanalysis and education, analyzing fundamental psychoanalytical concepts as reading operators for conducting research. We investigate the concepts of Unconscious and Other, accentuating their political dimension. Possible encounters between the two areas are highlighted, emphasizing the articulation between psychoanalysis, education and research. Specifics of the research are referenced, and the concepts of transference, free association, discourse and listening are analyzed, as methodological tools used in the research approach. Finally, we share proposals for current studies in which methodological resources built by the contribution of psychoanalysis are applied.

Keywords: Psychoanalysis; Education; Search.

Resumen: En el presente artículo proponemos discutir la relación entre el psicoanálisis y la educación, el análisis de los conceptos psicoanalíticos fundamentales como la lectura de los operadores en la realización de la investigación. Problematizar los conceptos inconscientes y otros, lo que acentúa su dimensión política. posibles encuentros entre las dos áreas se califican, lo que subraya la relación entre el psicoanálisis, la educación y la investigación. Detalles de la investigación se hace referencia y se analizaron los conceptos de transferencia, libre asociación, el habla y la escucha como herramientas metodológicas en el enfoque de investigación. Por último, compartimos las propuestas de estudios que actualmente se realizan en los que se aplican los recursos metodológicos construidos por la contribución psicoanalítica.

Palabras clave: El psicoanálisis; La educación; La investigación. 
Freud inaugura a psicanálise na virada do século XIX e desde sua inauguração entrelaça o fazer clínico com a pesquisa. Foi por meio da escuta de seus pacientes que o mestre vienense teceu seu edifício teórico e nos apontou o enlace entre a prática clínica e a construção conceitual. Mesmo não tendo se dedicado especificamente ao campo educacional, a elaboração freudiana inspira trabalhos que extrapolam o espaço da clínica individual e ocupam-se de áreas afins, sendo a educação uma delas.

Voltolini (2011) destaca que, embora não haja na obra de Freud nenhum texto no qual o autor se ocupe da educação de modo exclusivo, o tema acaba por aparecer de forma recorrente nos assuntos por ele abordados. Podemos visualizar tal vínculo, pois, conforme apresenta Pechberty $(2003$, p. 265$)$, a proposta freudiana do funcionamento do inconsciente "[...] trouxe um terreno fértil para os educadores e professores, envolvidos no laço com a infância e a adolescência" (tradução nossa). Segundo o autor, Freud apresentou, por exemplo, a noção de transferência amorosa ou hostil em jogo na relação entre o professor, seu saber e os alunos; bem como a repetição de imagens infantis que se atualizam no processo de ensino e aprendizagem, modulando o interesse, a rejeição ou a ambivalência dos alunos em relação ao conteúdo das disciplinas escolares e também com seus professores.

Tendo em vista esses apontamentos iniciais, neste trabalho temos como objetivo problematizar conceitos psicanalíticos centrais e sua operacionalização na pesquisa em educação. Para tanto, situamos o conceito de inconsciente como contribuição da psicanálise, sua escuta fora do setting clínico tradicional, bem como a dimensão política implicada no fazer psicanalítico. Problematizamos a transferência, a associação livre, o discurso e a escuta como recursos metodológicos para a realização de pesquisas na interface psicanálise e educação. Encerramos o artigo apresentando, a título de ilustração, alguns elementos de pesquisas propostas pelas autoras e que ainda estão em andamento, considerando esta interface e sua articulação com os pressupostos metodológicos que discutimos.

\section{INCONSCIENTE E OUTRO}

Pensar na aplicação da psicanálise, principalmente na sua articulação com a pesquisa de modo geral e com a educação em particular, é, antes de tudo, atentar para a compreensão de seus conceitos fundamentais. Consideramos de suma importância iniciar essa reflexão pelo conceito de inconsciente. Embora o conceito não tenha sido criado por Freud (2010c), pois já figurava na filosofia remetendo à ideia do que é "não consciente", foi sob sua pena que ele ganha o estatuto de instância psíquica, inaugura uma racionalidade própria, não se limitando a ser compreendido como oposto ao que é consciente. Na sua teorização sobre o inconsciente, o autor elabora duas abordagens conhecidas como tópicas.

Na primeira tópica, essa instância opõe-se ao sistema pré-consciente-consciente e é composta por elementos recalcados, cujo acesso é recusado à consciência. Para que o conteúdo 
inconsciente possa acessar a consciência, é necessário que o mesmo se transforme em uma representação que burle a censura e que seja aceita pelo sistema consciente. Isso ocorre pelos mecanismos de condensação e deslocamento ${ }^{1}$ (CHEMAMA e VANDERMERSCH, 2007).

Já na segunda tópica, Freud elabora outra denominação para as instâncias psíquicas, agora caracterizadas como Id (ou isso), Ego (ou eu) e Superego (super eu), sendo que o inconsciente qualifica o Id, mas também compõe parcialmente as instâncias do Ego e do Superego. Com a segunda tópica, o autor amplia a concepção de inconsciente agregando a ideia de que ele deve ser concebido como mote pulsional do psiquismo. A pulsão também se caracteriza como um conceito fundamental para a psicanálise e, grosso modo, remete à noção das modalidades de laço que o sujeito estabelece com os objetos, sendo concebida sempre no plural devido à sua diversidade. Distingue-se do conceito de instinto, pois esse abarca somente uma modalidade de relação com os objetos, não permitindo variações (CHEMAMA e VANDERMERSCH, 2007).

Outro psicanalista caro a essa problematização é Jacques Lacan. Lacan trabalha o conceito de inconsciente de diferentes modos, em diferentes momentos sociais e políticos dos quais é contemporâneo e introduz, como trabalho permanente do analista, compreender a subjetividade de seu tempo e a dinâmica própria das relações que se estabelecem ali. Certamente, a compreensão do inconsciente como algo que ultrapassa a dinâmica individual é fundamental para situarmos o lugar do analista fora do setting, presente nas discussões da cultura e da política de seu tempo. Avançamos no trabalho que Freud (1933/2010d) promoveu com a postulação do inconsciente quando desdobramos sua origem no Outro. Portanto, pensar o inconsciente a partir do social e do político é um trabalho permanente de construção do pensamento psicanalítico.

Se o inconsciente provém do laço social, é preciso elucidar de onde provém a fala, como ela se constitui, entendendo que os lugares sociais pré-interpretam e demandam certa alienação ao sujeito. Assim, quem fala, fala de que lugar? Que verdade essa fala veicula? O que ela demanda dos sujeitos a quem ela aliena?

A afirmação de Lacan no seminário 14 (1966-1967/2000), A lógica da fantasia, "o inconsciente é a política", requer uma análise da construção permanente que o autor realiza em torno do conceito de inconsciente. Com a compreensão de que o inconsciente ultrapassa as dimensões maniqueístas do dentro-fora, o analista tem que lidar com a política, com a dinâmica que enlaça os sujeitos numa determinada época. A esse respeito, Miller (2011, p. 4) pontua, em relação a essa afirmação lacaniana: "O inconsciente é a política provém do que liga e opõe 'os homens' entre eles, ou seja, o inconsciente provém do laço social".

Brousse (2003) adverte que essa definição contempla duas direções importantes para a ampliação do conceito de inconsciente. Numa direção, essa definição contempla e reafirma a do Seminário 11 (1988), pela qual o inconsciente é pensado como oriundo do discurso do Outro, e por isso mesmo, o sujeito é dividido e, por outro lado, traz a ideia de que o inconsciente tem que ver com o laço social, não se situando apartado dele, mas imerso em seus movimentos simbólicos, a partir de uma produção subjetiva que expressa algo desse laço. Assim, os discursos são movimentos simbólicos, sendo o sujeito um efeito a partir deles. 
Tomando como ponto de partida que o inconsciente marca esse ponto de junção entre o Outro e sua política como semblante, e o que é o mais particular do sujeito, Brousse (2003) se orienta a partir de um fragmento lacaniano, referente às vinculações entre o inconsciente e a política. Por ele define o trabalho do analista a partir dessa compreensão do inconsciente que ultrapassa a dinâmica individual.

Que antes renuncie a isto [à prática da psicanálise], quem não conseguir alcançar em seu horizonte a subjetividade de sua época. Pois, como poderia fazer de seu ser o eixo de tantas vidas, quem nada soubesse da dialética que o compromete com essas vidas num movimento simbólico. Que ele conheça bem a espiral a que o arrasta sua época na obra contínua de Babel, e que conheça sua função de intérprete na discórdia das línguas (LACAN, 1953/1998, p. 322).

Essa afirmação, que situa o inconsciente a partir de suas relações com a cultura, é do mesmo período histórico em que Lacan se utiliza da linguística para pensar o inconsciente estruturado como linguagem. É nesse sentido que Brousse (2003) destaca que o desejo não é, jamais, individual ou como sublinha Lacan (1998), o desejo é o desejo do Outro. Temos aí a marca da alienação do sujeito e de sua não essência, por essa cisão fundamental, como efeito da linguagem. Aqui se desfaz a concepção mais estrita da psicanálise como proposta que visa somente o particular, o subjetivo, como um discurso que valoriza e destaca especialmente uma essência do sujeito. É nessa esteira que sustentamos teoricamente a aplicação da psicanálise, por meio de uma não divisão radical entre o campo do Outro e o do sujeito, já que se trata sempre de alienação aos significantes primordiais, que advém da cultura. Seja no setting analítico em que a prática da psicanálise se origina, seja na cultura, em que ela questiona a posição do analista, vamos nos deparar, sempre, com as questões da alienação e da separação do sujeito.

Para não cairmos na tentação de situar uma consistência lógica no discurso do Outro, é preciso também considerar que a linguagem tem, sempre, uma dimensão histórica. Por ela, podemos vislumbrar uma dinâmica que encontra sua sustentação na falta primordial, também operante no Outro. Assim, a autora nos conduz:

Trata-se de decifrar \$ (S barrado), o significante do Outro que não existe, que só existe sob essa forma de significante, do movimento simbólico (...) Ou seja, o Outro, que se reduz ao conjunto de significantes, é um Outro que só existe como semblante (BROUSSE, 2003, p. 18).

Assim, a afirmação "o inconsciente é a política" traduz uma definição de inconsciente, que é estruturado no Outro e é, por isso mesmo, um modo de expressão subjetivada de uma época. Algo na análise não caminha sem o questionamento da política. E, do mesmo modo, o analista é chamado a atuar frente à cidade e ao arraste que os discursos simbólicos promovem. Assim, a autora convoca o lugar do analista para uma ética sempre marcada, quando nos diz: "o analista é alguém que forçosamente se compromete, que se envolve e que toma partido" (BROUSSE, 2003, p. 20). É importante, no entanto, considerar que essa posição do analista em resposta à concepção de um inconsciente político não desabona a neutralidade em relação ao desejo do sujeito. Mas a ressitua, como uma neutralidade no que diz respeito ao juízo que o analista pode fazer em relação às escolhas dos sujeitos. É uma neutralidade que articula um compromisso com o sujeito e, ao mesmo tempo, o respeito por suas escolhas. É, efetivamente, uma aposta na possibilidade da separação e da escolha do sujeito ante o Outro barrado. Como nos diz Lacan (1998, p. 260): "O inconsciente é a parte do discurso concreto, como transindividual, que falta à disposição do sujeito para restabelecer a continuidade de seu discurso consciente". 
Em outro trabalho (citação do trabalho do autor), discutimos a causação do sujeito e as possibilidades de separação que essa vinculação essencial ao Outro comporta. Ali nos perguntamos acerca das escolhas que têm o sujeito, já que se constitui a partir do Outro. Obviamente, a referência ao campo do Outro aqui situa a escolha do sujeito no que se refere ao inconsciente. Não nos referimos, deste modo, a qualquer sorte de escolha consciente, intenções ou vontades. Essa distinção é fundamental, pois "quando de algum modo o sentido se realiza em um sujeito em virtude da ação do Outro, deixa caído no caminho uma região de sem sentido. Essa região é, justamente, a daquilo que é inconsciente" (HARARI, 1990, p. 241).

$\mathrm{O}$ que poderia definir o ser de um sujeito? O que garantiria sua liberdade e escolhas se suas referências iniciais (na forma de significantes primordiais) são trazidas pelo Outro? Em outros termos, como pode o sujeito se definir se as definições trazem a marca do Outro? São questões que fundamentam a compreensão do inconsciente estruturado como linguagem, ponto de partida para pensarmos uma relação intrínseca com a política na base da causação do sujeito.

Lacan apresenta uma possibilidade de tomar tais questões a partir da análise das operações lógicas, a alienação e a separação (como também discutimos no artigo citado). A operação da alienação é "(...) a primeira operação essencial em que se funda o sujeito" (LACAN, 1988, p. 199). A identificação dá condição de que a fantasia de uma origem no Outro se instale, situando o Outro e o sujeito. Laurent reitera que "a alienação é o fato de que o sujeito, não tendo identidade, tenha de identificar-se a algo" (LAURENT, 1997, p. 43). É pela falta radical de identidade que a operação da alienação se constrói, numa busca de ancoramento simbólico que, em si, já porta as marcas políticas do Outro em sua flutuação, mutação permanente de alavancas simbólicas que definem um sujeito e/ou Outro, sempre históricos e politicamente determinados. Assim, com o acento lacaniano na falta, essa passa a operar na determinação de um sujeito, antes mesmo de qualquer definição de seu ser. De que falta se trata?

Para Laurent (1997), tal falta se articula ao resto do efeito da linguagem sobre o sujeito, já que no mesmo momento em que é representado pelo significante, com uma proposta de ser, esse sujeito não pode obter sua essência a partir desta representação. Ele encontra, deste modo, um ponto opaco de indefinição, manifestado pela angústia, parceira sempre atuante. As definições simbólicas podem ser pensadas, deste modo, como uma promessa de ser, concedida pelos significantes primordiais advindos do Outro, ao que a angústia sempre convoca. A esse respeito podemos ainda evocar o trabalho inicial de Freud (2010d) sobre o tema, ao indicar como representantes da pulsão o afeto (angústia, sobretudo) e a ideia. Lacan reintroduz essa costura, ao demarcar um limite real articulado ao trabalho simbólico.

Alienando-se, o sujeito tenta assumir suas identificações primárias; porém a impossibilidade está sempre ali, já que parte do Outro sua designação, expressão da fantasia inconsciente. Ainda que o sujeito se agarre às identificações primárias, provindas do Outro, o que ele encontra é apenas sua inconsistência (LACAN, 1988), já que não há coincidência absoluta entre o Outro e o sujeito.

Essas questões, fundamentais para a psicanálise, são cruciais na clínica, lugar por excelência do questionamento sobre o desejo e as escolhas do sujeito, mas também no campo da cultura, cujas determinações circulam a partir dos discursos e propõem respostas 
subjetivas padronizadas e mortificantes. Por outro lado, mesmo que falho em definir o ser do sujeito, o significante é a matéria-prima de sua constituição, que o cinde. Sem ele, não haveria nenhum sujeito no real (LACAN, 1998).

Como vimos, é central nessa discussão a problematização do conceito e da noção de discurso e para tanto nos centramos, sobretudo, na abordagem que Lacan estabelece do discurso, pelo avesso, como ele esclarece, ao definir posições discursivas inconscientes. Tratase de enfatizar o discurso que preexiste às palavras, fazendo aparecer os enunciados, que as definem e condicionam. Notemos, aqui, além disso, a presença de uma dinâmica própria entre as enunciações dos sujeitos e o enunciado do discurso, mais estrutural e prévio e que condiciona, em alguma medida, a alienação dos sujeitos. $O$ avesso da psicanálise que Lacan (1992) discute aqui toma o fundamento da própria palavra, a submete, esvaziando-a de sentido. Enfatiza, desta forma, um real da linguagem, anterior e mais fundamental do que a dimensão de sentido que ela carrega, sempre histórico e cultural. Podemos entender que o próprio significante é um elemento do discurso, numa redução ainda maior de um pretenso sentido presente na linguagem. Mas como isso se mostra na docência?

Pensar o inconsciente como político coloca a questão da aplicação da psicanálise e, ainda, congrega o chamado aos analistas para discutirem sua sociedade, os discursos que produzem as alienações, além de ratificar a ética própria da lida com o inconsciente (LOPES; BORGES, 2015). Para pensar a questão das relações entre a psicanálise e a política, então, é preciso que nos situemos, como analistas, em relação à nossa época, e especificamente em relação ao tema de nossas pesquisas. Assim, quais desafios e imposições estão nos atravessando em relação à docência?

\section{Alguns encontros entre a pSicAnálise e a educAÇÃo}

Como anteriormente mencionado, Freud não se dedicou diretamente a tematizar a educação em suas obras. De acordo com Cifali e Imbert (1999), o pensador vienense vinculou seu interesse pela educação às suas teorizações sobre a cultura. A cultura implica a repressão ou as renúncias por parte do sujeito, sendo que "o progresso da civilização passa pela sublimação de componentes pulsionais" (CIFALI e IMBERT, 1999, p. 19-20). Assim, conforme apontam os autores citados, a educação age justamente no cerne da contradição e do conflito entre pulsão e cultura. Sobre essa relação, Voltolini destaca ainda que

\footnotetext{
Em Freud, processo educativo e processo civilizatório aparecem como sinônimos. E ele destaca que, antes de criar um determinado tipo de homem, é na própria hominização que a educação encontra sua tarefa mais determinante. Toda vez que avança na discussão sobre o processo civilizatório, Freud extrai consequências para a educação. (VOLTOLINI, 2011, p. 48).
}

O autor citado avança na discussão sobre essa relação quando nos alerta que tal laço não enfoca propor modelos que sustentem uma boa relação entre professor e aluno ou as bases para a proposição de uma didática eficaz, mas sim questiona sobre "as condições de possibilidade de qualquer educação" (VOLTOLINI, 2011, p. 11). Aponta, ainda, para o engano de reconhecermos apenas uma direção pedagógica única que conduza o processo educativo a um bom termo. 
O próprio conceito de inconsciente introduz a ideia de que o controle e a previsibilidade educativos não podem ser totalmente realizados, daí sua dimensão insistentemente referida como impossível pela psicanálise. Ainda sobre essa dimensão, destaca:

\footnotetext{
Todo aquele que se aventurar no campo educativo (haverá alguém que possa escapar dele?) terá que se confrontar, mais cedo ou mais tarde, com a decepção. Os resultados atingidos estarão sempre aquém daqueles imaginados no ponto de partida. Entre os fins vaticinados e os meios postos em prática para a sua execução, quaisquer que sejam eles, haveria uma impossibilidade lógica (VOLTOLINI, 2011, p. 27).
}

Outra concepção apresentada pelo autor, e que nos auxilia a pensar o encontro da psicanálise com a educação, é o deslocamento que Freud propõe da ideia de educação para a ideia de educar. Além disso, destaca que não é exclusivamente como campo de conhecimento no qual a psicanálise pode ser aplicada que podemos reconhecer a educação, mas também como uma posição discursiva. Partindo desse deslocamento, o autor vai definir educar como

\begin{abstract}
O educar tem a ver com a transmissão de um traço simbólico de filiação, de uma marca que permite a um sujeito, primeiro, se erigir como sujeito, o que é diferente, portanto, da limitada configuração biológica com a qual precariamente nasceu (hominização). Depois, diferenciarse do outro que the rendeu os primeiros meios de entrada no mundo (singularização). E, por último, encontrar seu lugar no meio de outros com os quais terá que administrar sua diferença (socialização). (VOLTOLINI, 2011, p. 70).
\end{abstract}

A partir dessas breves proposições acerca da relação da psicanálise com a educação, no próximo tópico nos dedicamos a pensar a dimensão da pesquisa agregada a essas duas dimensões. Pensar a pesquisa em educação embasada pelo referencial psicanalítico implica problematizarmos as especificidades da psicanálise nessa articulação.

\title{
Psicanálise, EDUCAÇão E PESQUisa
}

Refletindo sobre como se conduz um docente em seu fazer cotidiano, Cifali (2004) pontua que um professor utiliza a invenção em seu cotidiano de um modo muito próximo do analista, especialmente no que diz respeito ao seu ato e sua ética com a diferença radical de seus alunos. Não se trata, para a autora, de experimentação no método que cada professor desenvolve como um processo ao longo de sua prática, mas de um saber inconsciente construído por força da experiência. Essa proximidade é construída no seu fazer, seu estilo e a construção de uma prática que não se faz sem um pouco de invenção. Do mesmo modo, a autora citada sustenta que essa proximidade é muito bem-vinda em se tratando de pesquisas que pretendam contemplar um laço entre psicanálise aplicada e educação. Não apenas os conceitos fundamentais da psicanálise, como o de inconsciente, repetição, pulsão, transferência, entre outros, estão em questão, quanto um lugar a partir do qual o pesquisador opera investigando e sendo investigado por seu objeto. Ainda para Cifali (2004, p. 58), em se tratando deste enlace, é preciso, como psicanalista que aplica sua escuta e seu olhar fora do setting habitual, "operar deslocamentos que tornem possíveis alguns deslocamentos".

Para que operar deslocamentos na prática da pesquisa? Por meio deles, a autora propõe desmobilizar entraves de todos os tipos no fazer educativo, abrindo espaço para a produção do novo numa prática que se constitui, muitas vezes, baseada na repetição no ato de transmitir 
e de ensinar. É a repetição, no mais das vezes, a maior queixa dos docentes, quando se referem às estereotipias próprias da escola, como a manutenção do fracasso escolar, da falta de motivação e indisciplina dos alunos, da precariedade do sistema educacional, dentre outros.

Cifali indica que é preciso pensar os atos envolvidos no processo de ensinar e aprender, enfrentá-los, a despeito da resistência, e até com o auxílio desta, na firme escolha de não ocultar os aspectos mais conflitivos, abrangendo sempre o mal-estar. Nesse sentido, define sua postura de pesquisadora como "interpretante", em que quer que aplique sua escuta de psicanalista. Para tanto, coloca como primeiro movimento do pesquisador psicanalista uma orientação que visa questionar como os sujeitos lidam com o saber em suas vidas, como o utilizam para se defenderem de suas próprias dificuldades com o embate com o que não sabem. Esclarece então a autora que a sua 'postura clínica', ou, como queremos, do pesquisador que sustenta sua ação na psicanálise aplicada, é "fundada na tensão entre subjetividade e intersubjetividade, com uma exigente preocupação com a alteridade" (CIFALI, 2004, p. 59). Concordamos com a autora e sustentamos que a subjetividade não se constitui, nem se mostra em suas muitas e complexas montagens, sem uma relação íntima e constituinte com a intersubjetividade, marcada por uma época e por modos de funcionamento do Outro.

Neste sentido, partimos de uma concepção que pretende superar internamente uma dicotomia entre indivíduo e sociedade, produções singulares e não transmissíveis e produções sociais, e que pensa o sujeito referido ao Outro cultural e social. Como afirma Rosa e Domingues (2010), para nós a pesquisa psicanalítica visa à elucidação da dimensão inconsciente constitutiva e constituída dos encontros e dos desencontros sociais e políticos. Além disso, concordamos com Pereira (2016, p. 70), quando enfatiza que "consideramos que a função da psicanálise aplicada à pesquisa deve ser a de colocar em suspeição qualquer concepção generalista de discurso, que, com seus métodos, sistemas e jogos de força, pode desprezar o lugar de experiências microfísicas, singulares e capilares".

Podemos pensar o desenho da pesquisa em psicanálise caracterizado no rol de pesquisas nomeadas como qualitativas, embora seja importante destacar as especificidades dessa abordagem na elaboração do trabalho investigativo. Rosa (2004) apresenta como possibilidade da pesquisa em psicanálise atrelada a uma prática denominada psicanálise extramuros ou em extensão, caracterizada pela problematização e pela investigação de fenômenos que não estão diretamente ligados ao enquadre do tratamento psicanalítico. Resgata que o próprio Freud, embora tenha se dedicado à construção da teoria psicanalítica fortemente vinculada à prática clínica, nomeou de psicanálise aplicada as contribuições de seus escritos que extrapolam esse campo. Nesse sentido, Nogueira (2004, p. 83) destaca que "a metodologia científica em psicanálise confunde-se com a própria pesquisa, ou seja, a psicanálise é uma pesquisa", seja ela realizada no contexto clínico ou em outros.

Por outro lado, diferentemente das pesquisas quantitativas e de algumas pesquisas qualitativas que se ancoram basicamente na descrição e na interpretação dos dados, a pesquisa psicanalítica está atenta às singularidades produzidas no discurso, ao modo singular do ser falante e não às regularidades ou grandes categorias. Igualmente, não está calcada na separação entre um sujeito que se ocupa da investigação e de um objeto foco de estudo. Sobre esses 
aspectos, Pereira (2016) destaca que o sujeito na pesquisa psicanalítica é alguém que constrói a pesquisa juntamente com o pesquisador e não sobre quem a pesquisa se desdobra.

A concepção de sujeito (que inclui necessariamente o conceito de inconsciente conforme já abordamos), a ética psicanalítica e o modo de formular as questões de investigação podem ser considerados como as contribuições específicas da psicanálise para a construção da pesquisa. Além disso, esclarece Rosa (2004, p. 341),

\begin{abstract}
O método psicanalítico vai do fenômeno ao conceito, e constrói uma metapsicologia não isolada mas fruto da escuta psicanalítica, que não enfatiza ou prioriza a interpretação, a teoria por si só, mas integra teoria, prática e pesquisa. O psicanalista não aplica teorias, não é o especialista da interpretação, nem mesmo da fantasia, posto que não é só aí que o inconsciente se manifesta; o psicanalista deve estar a serviço da questão que se apresenta. A observação dos fenômenos, está em interação com a teoria, produzindo o objeto da pesquisa, não dado a priori, mas produzido na e pela transferência.
\end{abstract}

Com o estabelecimento de uma relação transferencial, via escuta da associação livre, o sujeito que é "objeto" de pesquisa assume um lugar muito diferente de ser objeto de investigação sobre o qual se obtém um conhecimento (NOGUEIRA, 2004). A pesquisa psicanalítica ocupa-se da construção de caso e não na apresentação e na descrição de dados coletados e submetidos à interpretação teórica. Ainda nesse sentido, Pereira (2016, p. 72) afirma que "a perspectiva a ser considerada é a do caso único, de modo a não mecanizar a técnica, nem universalizar qualquer procedimento que se queira terminal".

\title{
A TRANSFERÊNCIA, A ASSOCIAÇÃO LIVRE, O DISCURSO E A ESCUTA COMO "INSTRUMENTOS" E ANÁLISE DOS "DADOS"
}

O conceito de transferência para a psicanálise está estreitamente vinculado com o método de tratamento proposto por Freud. Conforme destaca Maurano (2006, p. 15-16), o termo remete ao "[...] estabelecimento de um laço afetivo intenso [...] na relação com o médico, revelando o pivô em torno do qual gira a organização subjetiva do paciente". Nesse sentido, é a transferência que possibilita que o próprio processo analítico se instaure. A viabilidade do tratamento é vinculada, portanto, a esse investimento amoroso que o paciente faz no analista, supondo nele um saber que diz algo sobre o seu sofrimento. Quando essa relação é estabelecida, torna-se possível ao paciente reviver na cena analítica situações do passado, atualizando-as no presente da análise. De acordo com Maurano (2006, p. 20), "o fundamental não é a memória, mas a experiência da relação com o analista, na transferência. Só assim versões novas do velho conflito são criadas, possibilitando novas soluções". Nesse sentido, podemos considerar que é na transferência que o inconsciente se atualiza.

Lacan dedicou um dos seus seminários ao trabalho com o conceito de transferência (LACAN, 2010). Neste, resgata os apontamentos freudianos sobre o tema e inclui a dimensão da fala como central no processo transferencial. Segundo Lacan (2010, p. 221), "[...] parece-me impossível eliminar do fenômeno da transferência o fato de que ela se manifesta na relação com alguém a quem se fala". 
A transferência não é um fenômeno que ocorre somente na relação analítica, podendo estar presente em outros contextos de encontro, como é o caso da educação e da pesquisa no âmbito educacional. No que se refere à transferência na educação, tal conceito aparece como um dos principais quando tratamos da relação professor-aluno. Porém,

nesse caso, a diferença com aquilo que ocorre em uma análise está em que os dois parceiros estão presos, cada um por seu lado, a sua própria transferência, da qual, com muita frequência, não tem consciência; motivo pelo qual não é organizado o lugar de um intérprete, tal como o encarnado pelo analista, na situação de um tratamento analítico (CHEMAMA e VANDERMERCH, 2007, p. 377).

Em seu texto "Sobre a psicologia do colegial", Freud (2012) comenta que a personalidade dos professores mobiliza e constrói laço com os estudantes tanto ou mais que os conteúdos, pois entende que o acesso ao conhecimento é realizado por meio da pessoa do mestre. Nesse sentido, Kupfer esclarece que

pela via da transferência o aluno passará por ele - pelo professor -, usá-lo-á, por assim dizer, saindo dali com um saber do qual tomou verdadeiramente posse e que, constituirá a base e o fundamento para futuros saberes e conhecimentos (KUPFER, 1995, p. 100).

Freud ressalta a ambivalência dessa relação, pois os professores são alvo tanto do amor quanto do ódio de seus alunos operando, portanto, como herdeiros de sentimentos antes dirigidos aos seus pais ou cuidadores. Nas suas palavras,

Nós transferíamos para eles o respeito e as expectativas ligadas ao pai onisciente da infância,
e nos púnhamos a tratá-los como nossos pais em casa. Manifestávamos diante deles a
ambivalência que havíamos adquirido na família, e nessa atitude lutávamos com eles como
estávamos habituados a lutar com nossos pais carnais. Sem levar em conta as vivências infantis
e a vida familiar, nossa conduta ante os professores seria incompreensível, mas tampouco seria
desculpável (FREUD, 2012, p, 422-423).

Com essa reflexão, Freud nos convoca a pensar sobre o efeito que tal relação provoca tanto nos alunos quanto nos professores, lembrando que esse processo ocorre a partir da dinâmica inconsciente. Para Speller (2004, p. 36), "é essencial que o professor conheça esse conceito para entender as implicações de seu lugar: sua profissão", indo além das técnicas e dos métodos de ensino e lidando com sua profissão de modo mais abrangente. No que tange ao fenômeno transferencial no contexto da pesquisa em psicanálise e educação, Pereira (2016) trata também das mesmas questões, sublinhando que

cabe então à pessoa do pesquisador-interventor ofertar-se como objeto da transferência para escutar os efeitos advindos desses momentos nos quais o inconsciente comunica alguma verdade parcial do sujeito falante através de seus gestos, falas e discursos (PEREIRA, 2016, p. 76).

O autor ainda alerta para a necessidade de termos presente uma inversão da demanda que ocorre classicamente no setting clínico: quando é o sujeito que procura um espaço analítico, este apresenta a sua demanda, ao contrário da proposta de pesquisa na qual a demanda inicial é do pesquisador. Embora a demanda parta do pesquisador, pois ele convoca os sujeitos a falarem algo acerca do que lhe interessa como questão de investigação, é necessário que a pesquisa utilize ferramentas que possibilitem ao sujeito liberdade de construir seus movimentos associativos, uma das pedras basilares na construção da psicanálise. De acordo com Chemama e Vendermersch (2007), Freud começou a elaborar o método de associação livre a partir do tratamento de uma de suas pacientes que solicitou que o mestre vienense não intervisse 
no curso de sua fala, deixando que ela pudesse expressar-se livremente. Ainda conforme os autores, tal método passa a substituir o método catártico anteriormente empregado por Freud (2014) em 1898, tornando-se o instrumento privilegiado de acesso ao inconsciente.

Tal como a transferência e a associação livre, o conceito de escuta, ancorado na ideia de atenção flutuante ${ }^{2}$, tem papel central na práxis do psicanalista e, em extensão, do pesquisador que constrói sua pesquisa ancorada nos pressupostos da psicanálise. Se Freud (2010c; 2014) considerou a associação livre do paciente como forma de manifestação do inconsciente, em contrapartida postulou a escuta e a atenção flutuante como "instrumento" do psicanalista para ter acesso a tal manifestação. De acordo com Rosa (2004, p. 342), "o sujeito do inconsciente está presente em todo enunciado, recortando qualquer discurso pela enunciação que o transcende". Nesse sentido, é por meio da sua fala que podemos enfatizar a singularidade do sujeito, bem como nos possibilita aproximarmo-nos de seu desejo. Conforme ressalta Bastos (2009, p. 95),

\begin{abstract}
A escuta psicanalítica, como já destacado, é aquela que busca a singularidade do sujeito e que precisa estar atenta ao desejo inconsciente que está sendo enunciado. Singular é aquilo que é só seu, próprio de você e de mais ninguém, porque diz respeito a algo que foi se construindo e continua a se construir em sua história pessoal. O desejo (que é diferente da vontade), tem a ver com essa história e com a singularidade.
\end{abstract}

Em relação às "ferramentas" que possibilitem a escuta, concordamos com Rosa (2004) quando a autora enfatiza que podemos ampliar a escuta do inconsciente por meio de diversas produções humanas. Desta forma, a utilização de depoimentos, entrevistas, relatos, tomada a partir de um tema geral pelo pesquisador, revela-se legítima como instrumento de pesquisa psicanalítica, ancorada na associação livre a partir do discurso, e que leva o pesquisador a reconstruir a questão inicialmente colocada em seu projeto.

O trabalho realizado por Pereira, "O nome atual do mal estar docente" (PEREIRA, 2016), apresenta de forma rica o testemunho do autor na condução da pesquisa em psicanálise e educação. Como ferramentas metodológicas, aponta a pesquisa-intervenção de orientação clínica e a entrevista de orientação clínica. Na primeira, foram construídos espaços coletivos de fala para docentes e na segunda uma escuta individual realizada com professores. A partir de ambas as estratégias, o pesquisador enfatiza a importância dos espaços de fala destacando que

a orientação clínica baseia-se no ato de recordar, repetir e elaborar; e do ponto de quem conduz a pesquisa-intervenção, tal orientação centra-se no ato de fazer falar, intervir e propiciar desidentificações, dessubstancializações ou deslocamentos subjetivos (PEREIRA, 2016, p. 83).

Novamente, Rosa (2004, p. 344) nos auxilia a elucidar o lugar da escuta como central na pesquisa em psicanálise, sublinhando que não apenas um sujeito está enunciando sua fala acerca do que o causa e de como os significantes da cultura produzem alienações em seu ser, mas que sua escuta também testemunha e resgata uma memória, reconstruindo um lugar e uma ética, tanto para o sujeito quanto para o pesquisador.

Nesse sentido, o discurso dos participantes envolvidos na pesquisa de interface entre a psicanálise e a educação pode ser tomado a partir dos pressupostos da transferência e da associação livre nos espaços de fala e os "dados" colhidos não são tratados como fatos em si, mas sim como significantes que remetem a cada história, singular e desejante: 
[...] o método lacaniano [de análise do discurso] observa a presença concreta do discurso, das palavras e da linguagem, do que se diz e da maneira que se diz, e não do que tudo isso supostamente quer dizer (PAVÓN-CUELLAR, 2014, p. 194, grifo nosso).

A partir dos relatos dos participantes, podemos construir laço entre suas histórias e os conceitos da psicanálise. Buscamos com esta análise ora apresentada pensar como se sustenta esta tensão entre a subjetividade do professor e a intersubjetividade atual. Nesse sentido, pretendemos salientar o discurso inconsciente presente na transmissão que o professor efetua cotidianamente, num laço entre sua subjetividade e o Outro do qual dá testemunho. Como delineia Lacan (1992), quando demarca o lugar do sujeito, como suposto a um campo já estruturado de saber, campo já estruturado no Outro. Nessa perspectiva, adotamos uma metodologia aberta à complexidade de nosso objeto, que se constrói na medida em que o novo se apresenta, real.

Tomamos experiências e entrevistas na expectativa de que teoria e prática, clínica e teorização tensionam uma a outra, deixando a descoberto o que há de real no processo de simbolizar as relações e seus impasses. Nestes termos, Pereira (2012), que também trabalha a partir de entrevistas livres, como já discutimos mais acima, denominadas por ele como "clínicas", enfatiza que as mesmas têm esse viés em virtude do que alcançam - uma retificação subjetiva ou, pelo menos, um questionamento do próprio discurso. Mas o autor entende essa dimensão subjetivante de tais entrevistas também porque elas tocam em pontos de entrecruzamento sintomático, já que acabam por salientar temas do campo da clínica psicanalítica, como a subjetivação e a análise do discurso que estrutura as relações dos sujeitos envolvidos em determinada dinâmica. Tocam a repetição presente no ato de educar e promovem uma perlaboração da fala e do fazer. Deste modo, estas incursões pela vida, por meio das entrevistas, dão margem a situarmos um pouco mais algumas hipóteses gerais sobre as relações constitutivas entre o sujeito da civilização atual e a experiência psicanalítica.

\section{Algumas nOtAs SOBRE A ESCUTA DE PROFESSORES: OPERANDO A PESQUISA}

Após a incursão sobre os conceitos fundamentais da psicanálise, sua relação com a educação e, principalmente, com a pesquisa em educação ancorada na psicanálise, passamos nesse último tópico a apresentar algumas investigações que estão sendo realizadas pelas autoras, ainda em caráter preliminar. Nosso intuito é anunciar como os conceitos psicanalíticos e propostas de pesquisa podem ser profícuos na construção de conhecimentos no enlace psicanálise e educação.

A primeira proposta de pesquisa trata da investigação sobre o que mobiliza alunos de licenciatura a escolherem a docência como profissão. Partimos da análise do conceito de escolha para a psicanálise, diferenciando-o de abordagens positivistas. Para a psicanálise, uma escolha racional não esgota os fatores mobilizadores para que a eleição de uma profissão seja efetivada, pois encontramos entre eles o funcionamento da dinâmica inconsciente. 
Como conceitos balizadores para as futuras análises a serem realizadas no desenvolvimento da referida pesquisa, elencamos a transferência e a docência como sintoma. Nossa hipótese sobre a transferência gira em torno da ideia de que o sujeito que opta pela docência como profissão foi estabelecendo ao longo da vida relações de transferência não só com seus professores, mas também com os conteúdos que pretende ministrar como professor (CAMARGO, 2006; KUPFER, 2000). Já a docência como sintoma nos sinaliza para os modos singulares que o sujeito encontra para ir constituindo-se como docente, sendo o sintoma entendido aqui como produção e invenção do sujeito (LACAN, 2007; PEREIRA, 2013).

No que se refere aos aspectos metodológicos, partimos das considerações apontadas ao longo desse trabalho, elegendo como participantes alunos de licenciaturas que se dispuserem a narrar seu percurso de escolha do curso e a relação que foram estabelecendo com a educação ao longo de sua vida. Como instrumentos optamos por uma escrita livre sobre a temática e a entrevista com aqueles que desejarem esse espaço de fala mais individual e próximo com a pesquisadora. A partir dos relatos a serem colhidos junto aos participantes, construiremos laço entre as suas histórias e os conceitos, especialmente os conceitos de desejo, transferência e docência como sintoma. Nosso interesse não está em estabelecer uma verdade generalizável sobre o que mobiliza alunas/os a escolherem a docência como profissão, mas sim acompanhar os fios da história de cada um/a e os enlaces que esses discursos forem tecendo com os seus desejos.

A segunda pesquisa parte da compreensão de que a escola é um universo linguístico recheado de variados discursos latentes e manifestos, que convocam e orientam relações e vínculos, também conscientes e inconscientes. Dedicamo-nos a discutir como os variados discursos inconscientes circulam e se sucedem na escola, ainda que o universo escolar seja o campo por excelência do discurso do mestre. Entendemos que o sujeito tem suas relações determinadas pela linguagem, em sua condição de falantes (LACAN, 2003). Mas que relações são essas e como elas se apresentam no cotidiano da escola? Para pensar essa questão fundamental, tomamos como operador central o brincar na educação infantil, ponto de ancoragem da subjetividade e ponto de resistência política em tempos de infância dominada pelo brincar virtual (Levin, 2007).

A intensa atividade inconsciente que o brincar expressa o situa como fenômeno de articulação de muitos conceitos que tocamos aqui: inconsciente, linguagem, escola, sujeito, cultura. A esse respeito, Winnicott (1985) destaca que o brincar pode servir a muitas finalidades, como obtenção de prazer, organização mais geral da personalidade, domínio de angústias e adiamento das mesmas, controle de ideias, aquisição de experiências, iniciação social, dentre outras. Tomaremos como o brincar tem lugar na compreensão de professores da educação infantil, partindo da suposição teórica de que esse lugar tem relações inequívocas com a compreensão do sujeito na escola. No aprofundamento do conceito de inconsciente, pretendemos circunscrever as relações deste com a cultura e a dinâmica do Outro social, conforme tratados por Lacan (2003). Estes esforços serão o ponto de partida para análise do discurso de professores da educação infantil, que serão entrevistados por nós no modelo de entrevistas semiestruturadas, com viés clínico, sobre sua prática e sua compreensão da importância do brincar na constituição da subjetividade da criança. 
Os fenômenos transferenciais que poderemos observar nos discursos dos professores dirigidos a nós nas duas pesquisas em andamento indicarão um caminho de análise dos discursos inconscientes na atualidade, em especial, no encontro com o campo da educação. Nesse sentido, o conceito de transferência, nascido no interior do enquadre analítico de Freud (1912/2010a), poderá ser ampliado com a definição lacaniana de que ela é a manifestação do inconsciente como discurso do Outro (1988), produzido em sua variação cultural e histórica. Ela se revela manifestação inconsciente estereotipada, que se antecipa às novas relações e se constitui na tensão entre o coletivo e o particular, carregando as marcas do gozo de uma determinada época. No artigo apresentado buscamos discutir os meandros que articulam tais marcas.

\section{REFERÊNCIAS}

BASTOS, A. B. B. I. A escuta psicanalítica e a educação. Psicólogo informação, São Paulo, v. 13, n. 13, p. 91-98, jan./dez. 2009.

BROUSSE, M. H. O inconsciente é a política. São Paulo: Escola Brasileira de Psicanálise, 2003.

CAMARGO, A. C. C. S. de. Educar: uma questão metodológica? proposições psicanalíticas sobre o ensinar e o aprender. Petrópolis, RJ: Vozes, 2006.

CIFALI, M. Bagagem de uma educadora clínica no país do ensino e da educação. Psicologia em Revista, Belo Horizonte, n. 10, v. 15, p. 57-70, jun. 2004.

CIFALI, M.; IMBERT, F. Freud e a pedagogia. São Paulo: Edições Loyola, 1999.

CHEMAMA, R.; VANDERMERSCH, B. Dicionário de Psicanálise. São Leopoldo: Editora Unisinos, 2007.

DOR, J. Introdução à leitura de Lacan. Porto Alegre: Artmed, 1989.

FREUD, S. A fixação no trauma, o inconsciente. In: . Obras completas, volume 13: Conferências introdutórias à psicanálise (1916-1917). Tradução Paulo César de Souza. $1^{a}$ ed. São Paulo: Companhia das Letras, 2014, p. 364-380.

FREUD, S. Sobre a psicologia do colegial. In: Obras completas, volume 11: totem e tabu, contribuição à história do movimento psicanalítico e outros textos (1912-1914). Tradução Paulo César de Souza. $1^{a}$ ed. São Paulo: Companhia das Letras, 2012, p. 418-423.

FREUD, S. Recordar, repetir e elaborar. In: Obras completas, volume 10: Observações psicanalíticas sobre um caso de paranoia relatado em autobiografia ("O caso Schreber"), Artigos sobre a técnica e outros textos (1911-1913). Tradução Paulo César de Souza. $1^{a}$ ed. São Paulo: Companhia das Letras, 2010a, p. 193-209.

FREUD, S. A repressão. In: Obras completas, volume 12: Introdução ao narcisismo, Ensaios de metapsicologia e outros textos (1914-1916). Tradução Paulo César de Souza. $1^{a}$ ed. São Paulo: Companhia das Letras, 2010b, p. 82-98.

FREUD, S. O inconsciente. In: Obras completas, volume 12: Introdução ao narcisismo, Ensaios de metapsicologia e outros textos (1914-1916). Tradução Paulo César de Souza. $1^{a}$ ed. São Paulo: Companhia das Letras, 2010c, p. 99-150.

FREUD, S. A dissecção da personalidade psíquica. In: Obras completas, volume 18: O malestar na civilização, Novas conferências introdutórias à psicanálise e outros textos (1930-1936). Tradução Paulo César de Souza. $1^{a}$ ed. São Paulo: Companhia das Letras, 2010d, p. 192-223. 
FREUD, S. Recomendações aos médicos que exercem psicanálise. In: Coleção completa das obras de Sigmund Freud, v. XII. Rio de Janeiro: Imago, 1969.

HARARI, R. Uma introdução aos quatro conceitos fundamentais de Lacan. Campinas, SP: Papirus, 1990.

KUPFER, M. C. M. Educação para o futuro: psicanálise e educação. São Paulo: Escuta, 2000.

KUPFER, M. C. M. Freud e a educação. São Paulo: Scipione, 1995.

LACAN, J. O seminário, livro 8: a transferência (1960-1961). Rio de Janeiro: Zahar, 2010.

LACAN, J. O seminário, livro 23: o sinthoma (1975-1976). Rio de Janeiro: Zahar, 2007.

LACAN, J. Proposição de 9 de Outubro de 1967 sobre o psicanalista da Escola. In: Outros Escritos. Rio de Janeiro: Jorge Zahar Editor, 2003, p. 248-264.

LACAN, J. Função e campo da fala e da linguagem em psicanálise - 1953. In: Escritos. Rio de Janeiro: Jorge Zahar Editor, 1998, p. 238-324.

LACAN, J. O seminário, livro 17: o avesso da psicanálise (1969-1970). Rio de Janeiro: Jorge Zahar Ed, 1992.

LACAN, J. O seminário, livro 11: os quatro conceitos fundamentais da psicanálise (1964). Rio de Janeiro: Jorge Zahar Ed, 1988.

LACAN, J. Seminário 14. La lógica del fantasma (1966-1967). Versão não estabelecida, s/d.

LEVIN, E. Rumo a uma infância virtual? $1^{\text {a }}$ ed. Petrópolis: Vozes, 2007.

LEVIN, E. Clínica e educação com as crianças do outro espelho. Petrópolis: Vozes, 2005.

LOPES, A. C.; BORGES, V. Formação docente, um projeto impossível. Cadernos de Pesquisa, v. 45, n. 157, p. 486-507, jul./set. 2015.

MAURANO, D. A transferência. Rio de Janeiro: Jorge Zahar Editor, 2006.

MILLER, J. A. Intuições milanesas. Revista Opção lacaniana online, v 2, n. 5, p. 1-15, jul. 2011.

NOGUEIRA, L. C. A pesquisa em psicanálise. Psicologia USP, n. 15, v. 1-2, p. 83-106, jan./jun. 2004.

PAVÓN-CUÉLLAR, D. Do método lacaniano crítico-teórico às suas reconfigurações prático-políticas em discursos concretos: questionamento da ideologia, compromisso do pesquisador e subversão do sujeito. In: LIMA, A. F.; LARA JÚNIOR, N. (Org.). Metodologias de pesquisa em psicologia social crítica. Porto Alegre: Sulina, 2014, p. 193-232.

PECHBERTY, B. Apports actuels de la psychanalyse à l'education et l'enseignement: um éclairage fécond. Ela - Études de linguistique appliquée. N. 131, p. 265-273, 2003.

PEREIRA, M. R. O nome atual do mal-estar docente. Belo Horizonte: Fino Traço, 2016.

PEREIRA, M. R. O professor-sintoma. Correio da APPOA, Ano 1, n. 1, p. 33-39, jan. 2013.

PEREIRA, M. R. Acabou a autoridade? Professor, subjetividade e sintoma. São Paulo: Fino Traço Editora, 2012.

PISETTA, M. A. A. M. Linguagem e cotidiano escolar: contribuições da psicanálise. In: LEHMANN, L.; COUTINHO, L. (Org.) Psicologia e educação: interfaces. Niterói: Eduff, 2015, p. 111-122. 
PISETTA, M. A. A. M.; BESSET, V. L. Alienação e separação: elementos para discussão de um caso clínico. Psicologia em Estudo, Maringá, v. 16, n. 2, p. 317-324, abr./jun. 2011.

ROSA, M. D. A pesquisa psicanalítica dos fenômenos sociais e políticos: metodologia e fundamentação teórica. Revista Mal-Estar Subjetividade, n. 4 v. 2, p. 329-348, set. 2004.

ROSA, M. D.; DOMINGUES, E. O método na pesquisa psicanalítica de fenômenos sociais e políticos: a utilização da entrevista e da observação. Psicologia \& Sociedade, n. 22, v. 1, p. 180-188, jan./abr. 2010.

SPELLER, M. A. R. Psicanálise e Educação: caminhos cruzáveis. Brasília: Plano Editora, 2004.

VOLTOLINI, R. Educação e psicanálise. Rio de Janeiro: Zahar, 2011.

WINNICOTT, D. A criança e o seu mundo. Rio de Janeiro: Jorge Zahar, 1985.

Artigo recebido em: 02/10/2017

Aprovado em: 02/05/2018

Contato para correspondência:

Maria Angélica Augusto de Mello Pisetta.

E-mail: angelicapisetta@gmail.com

1 O primeiro definido como acúmulo de sequência de pensamentos em um elemento representativo e o segundo pelo foco em elemento que aparentemente não tem importância. Lacan irá aproximar a noção de condensação com o conceito de metáfora e a de deslocamento com a ideia de metonímia.

2 Chemama e Vendermersch (2007, p. 44) esclarecem que a atenção flutuante demanda do analista não atribuir importância a nada específico, além de que "[...] pressupõe, pois, da parte do praticante, a supressão momentânea de seus pré-julgamentos conscientes e de suas defesas inconscientes". 